\title{
Folate status of Ghanaian populations in London and Accra
}

\author{
Matilda Owusu ${ }^{1}$, Jane Thomas ${ }^{1}$, Edwin Wiredu $^{2}$ and Maria Pufulete ${ }^{1 *}$ \\ ${ }^{1}$ Nutritional Sciences Division, King's College London, 150 Stamford Street, London SE1 9NH, UK \\ ${ }^{2}$ School of Allied Health Sciences, College of Health Sciences, KB 143, University of Ghana, Legon, Ghana \\ (Received 1 October 2008 - Revised 28 July 2009 - Accepted 4 August 2009 - First published online 14 October 2009)
}

Migration to the UK is associated with higher incidence of stroke in African populations. A low folate status has been associated with increased risk of stroke, likely to be mediated through raised plasma homocysteine concentrations. We conducted a cross-sectional study to compare blood folate and homocysteine concentrations in eighty healthy Ghanaian migrants living in London matched by sex, age and occupation to 160 individuals from an urban population in Accra, Ghana. Folate intake was determined using three $24 \mathrm{~h}$ recalls. Fasting blood samples were collected for the determination of serum and erythrocyte folate and plasma homocysteine concentrations and the methylenetetrahydrofolate reductase (MTHFR) $677 \mathrm{C} \rightarrow \mathrm{T}$ polymorphism. Reported mean folate intake was $20 \%$ lower in London compared with Accra $(P<0 \cdot 001)$. However, serum folate was $44 \%$ higher, erythrocyte folate $30 \%$ higher and plasma homocysteine was $26 \%$ lower in subjects from London compared with those from Accra $(P<0 \cdot 001)$. These differences persisted after adjusting for confounders including the MTHFR $677 \mathrm{C} \rightarrow \mathrm{T}$ mutation, which was rare in both populations. Although there were no associations between dietary folate intake and blood folates $(P>0 \cdot 05)$, folic acid supplement use, which was more prevalent in London than Accra ( 25 and $10 \%$, respectively, $P=0.004)$ was associated with erythrocyte folate in both populations $(P<0.01)$. The main predictors of plasma homocysteine concentrations were erythrocyte folate and male sex $(P<0 \cdot 001)$. Findings from the present study suggest that migration from Ghana to the UK results in improvement of biomarkers of folate status despite the fact that reported dietary intake of folate was apparently lower in subjects from London.

Folate: Homocysteine: Ghana: United Kingdom

People of African origin living in the UK have a higher incidence and mortality from stroke than white people ${ }^{(1,2)}$. Changes in dietary patterns are likely to contribute to these differences, particularly since migration to the UK has been associated with increased incidence of stroke ${ }^{(3)}$. A low folate status increases the risk of stroke ${ }^{(4)}$ and a recent meta-analysis of randomised controlled trials has shown that folic acid supplementation reduces the risk in primary prevention ${ }^{(5)}$. Folic acid may prevent stroke by lowering raised plasma homocysteine concentrations, which have been linked to endothelial dysfunction ${ }^{(6)}$.

Folate status can be determined by assessing dietary intake of folate and measuring serum and erythrocyte folate (which reflect recent dietary intake and tissue levels, respectively). Plasma homocysteine is also used as a functional indicator of folate status since homocysteine concentrations rise even with marginal folate depletion ${ }^{(7)}$. Clinical trials have shown that moderately increasing folate intake from dietary sources and vitamin supplements can reduce homocysteine concentrations effectively ${ }^{(8,9)}$. In white populations, a common mutation in a critical enzyme in folate metabolism, methylenetetrahydrofolate reductase (MTHFR $677 \mathrm{C} \rightarrow \mathrm{T}$ ), is a major determinant of plasma homocysteine concentrations, but the prevalence of this polymorphism is low in populations of African descent ${ }^{(10-12)}$; therefore folate status is likely to be the main determinant of homocysteine concentrations in these individuals.

There are no data comparing folate status in UK African migrants with populations from their country of origin (sedentes). A recent study has reported lower serum folate and higher plasma homocysteine in healthy Afro-Caribbeans in the UK compared with a matched population in Jamaica ${ }^{(13)}$. However, studies comparing folate and homocysteine concentrations in other ethnic populations in the UK have reported opposite effects; for example, UK Gujeratis had higher dietary folate intakes and serum folate and lower plasma homocysteine than those in India ${ }^{(14)}$. This indicates the need for ethnic group-specific studies to identify diet-related biomarkers that may influence risk of disease.

Ghanaians form the UK's fifth largest group of African migrants, with an estimated 50000-1000000 individuals living in London ${ }^{(15)}$. To our knowledge there is no available information on the folate status of Ghanaian migrants in the UK or in their country of origin. In the present study, we compared dietary folate intakes, serum and erythrocyte folate and plasma homocysteine concentrations in a Ghanaian migrant population in the UK matched with an urban population from Accra, Ghana, and determined the predictors of plasma homocysteine concentrations in this population. The MTHFR $677 \mathrm{C} \rightarrow \mathrm{T}$ polymorphism was determined 
to confirm its low prevalence in this population and account for any confounding effects on plasma homocysteine concentrations.

\section{Methods \\ Study population}

Subjects in the present study were part of a cross-sectional study examining the relationship between diet and CVD risk factors in two Ghanaian populations: a first-generation Ghanaian migrant population in London, and an urban population in Accra, Ghana, their country of origin. A total of 240 healthy subjects (London, eighty subjects; Accra, 160 subjects) aged between 25 and 50 years were recruited from Ghanaian organisations in London and Accra. In order to provide robust comparisons, subjects in London were matched for age ( \pm 2 years), sex and occupation to participants from Accra. Matching was done prospectively. Two Accra-based participants were matched to one London-based participant. London-based participants were included if they were aged between 25 and 50 years and had resided in the UK for at least 5 years. Participants were ineligible if they were diabetic, pregnant or lactating or had any major underlying organ pathology.

Participants recruited into the study reported at the approved study centres in London and Accra and were assessed regarding demographic characteristics, folate intake, serum and erythrocyte folate, serum vitamin $\mathrm{B}_{12}$ and plasma homocysteine concentrations with questionnaires, interviews, physical examination and blood sampling. The study was carried out according to protocols approved by the King's College London and University of Ghana Ethics Committees.

\section{Anthropometric measurements}

Participants underwent standard physical measurements including weight, height, waist circumference and blood pressure. Weight was measured with a Seca 762 scale (Vogel \& Halke, Hamburg, Germany) to the nearest $0.1 \mathrm{~kg}$ in light clothing with subjects standing erect. Height was measured using a portable stadiometer and made to the nearest $0 \cdot 1 \mathrm{~cm}$. The BMI was calculated by dividing the body weight (in $\mathrm{kg}$ ) by the square of the height (in metres).

\section{Dietary assessment and general characteristics questionnaire}

A self-administered questionnaire was used to obtain data about demographic characteristics, use of dietary supplements, health status, prescribed medications, and smoking and drinking habits. The questionnaire was pre-tested in a pilot study after which minor additions and changes were made to make it more presentable. Dietary intake was collected by a trained dietitian using the $24 \mathrm{~h}$ recall method for $3 \mathrm{~d}$ including a weekend day. The first interview was done on the day participants reported at the study centres and the further two were performed on the phone within the same week. Portion sizes were estimated using household measures common to the Ghanaian community.

\section{Calculation of dietary folate intake}

Nutrient intakes were estimated using the nutritional package Microdiet (version 1.2 software; Downlee Systems Ltd, Chapel-en-le-Frith, Derbys, UK) with an added database incorporating McCance and Widdowson's compositional data on immigrant groups and an updated database on the nutritional composition of commonly consumed Ghanaian dishes (M Owusu, unpublished results). Food folate and synthetic folic acid added to foods is handled as a single value in Microdiet. Folate content of the Ghanaian dishes was determined by microbiological assay using Lactobacillus rhamnosus (American Type Culture Collection (ATCC) 7469) after thermal extraction and tri-enzyme treatment ${ }^{(16)}$.

\section{Biochemical assessment}

Fasting blood samples were obtained in the morning after a $12 \mathrm{~h}$ fast. For serum folate and vitamin $\mathrm{B}_{12}$ measurement, blood samples were collected into a vacutainer containing no anticoagulant, left to clot for $1 \mathrm{~h}$ at room temperature and then centrifuged at $2500 \mathrm{rpm}$ for $15 \mathrm{~min}$. Serum was transferred into plastic vials and frozen immediately. Blood samples for analysis of erythrocyte folate were collected into vacutainers containing EDTA and sent to the laboratory within $24 \mathrm{~h}$ of collection for full blood count and folate analyses. In Accra, it was not possible to run the assay for serum and erythrocyte folate; therefore, serum and whole blood samples were frozen at $-80^{\circ} \mathrm{C}$ and shipped to London for analyses. However, full blood counts were performed in Accra within $24 \mathrm{~h}$ of blood collection. Fasting blood samples for homocysteine determination were collected into EDTA-containing vacutainer tubes, placed on ice and carried to the laboratory where the plasma was centrifuged at $3000 \mathrm{rpm}$ for $10 \mathrm{~min}$, transferred into plastic vials and frozen at $-80^{\circ} \mathrm{C}$ until analysis. For DNA extraction, whole blood samples were collected into vacutainer tubes containing EDTA and frozen at $-80^{\circ} \mathrm{C}$ until required for DNA extraction. Samples from Accra were transported on dry ice to King's College London and refrigerated at $-70^{\circ} \mathrm{C}$ until the analyses were performed.

\section{Laboratory analysis}

All samples were analysed at the Department of Clinical Biochemistry at King's College Hospital, London. Serum folate, $\mathrm{B}_{12}$ and erythrocyte folate were analysed using the Bayer Advia Centaur folate kit (Bayer Diagnostics Europe Ltd, Swords, Co. Dublin, Republic of Ireland) and plasma homocysteine by the Bayer Advia Centaur homocysteine kit (Bayer Diagnostics Europe Ltd). For all assays, the withinrun $\mathrm{CV}$ was $<2.2 \%$ and between-run $\mathrm{CV}$ was $<5.2 \%$.

\section{DNA extraction}

The DNA for genotyping was extracted from whole blood using the Puregene DNA isolation kit (product number D5000; Gentra Systems, Inc., Minneapolis, MN, USA). DNA fragments were amplified from the genomic DNA with the PCR. The MTHFR $677 \mathrm{C} \rightarrow \mathrm{T}$ substitution was identified with the use of restriction enzyme digestion of the 
PCR-amplified products, as previously described by Frosst et al. ${ }^{(17)}$. The PCR product was digested using Hinf I (GE Healthcare, Chalfont St Giles, Bucks, UK). The $677 \mathrm{C} \rightarrow \mathrm{T}$ polymorphism creates a Hinf I recognition site in a $198 \mathrm{bp}$ amplified DNA fragment. This was used to differentiate the various genotypes: $\mathrm{CC}, \mathrm{CT}$ and $\mathrm{TT}$.

\section{Statistical analysis}

Statistical analyses were performed using SPSS for Windows (version 14; SPSS, Inc., Chicago, IL, USA). Nutrient intakes were adjusted for energy using the method of residuals. This involved computing residuals from a regression model with energy intake as the independent variable and folate intake as the dependent variable ${ }^{(18)}$. Residuals were then added to the mean folate intake for the group to obtain a score adjusted to the average energy intake. To compare differences in categorical variables between groups, $\chi^{2}$ tests or Fisher's exact tests were used. Independent-sample $t$ tests were used to compare differences in age and BMI between locations, as these variables were normally distributed. Nutrient intakes (vitamin $\mathrm{B}_{6}$, vitamin $\mathrm{B}_{12}$ and folate) and biomarkers (serum and erythrocyte folate, serum vitamin $\mathrm{B}_{12}$ and plasma homocysteine) were skewed and transformations failed to normalise the data; therefore Mann-Whitney $U$ tests were used to compare differences between these variables. To test for the effect of potential confounders the analyses were repeated adjusted for age, sex, BMI, educational level, alcohol intake and the MTHFR genotype. Since the adjustment did not have any influence on the observed differences, only the unadjusted data are presented. Spearman's correlation coefficients were used to investigate the relationship between nutrient intakes and biomarkers and between MTHFR genotype and blood folates and plasma homocysteine. Multiple linear regression adjusting for the set of potential confounders described above was used to examine predictors of blood folate and homocysteine concentrations in each population. Differences were considered significant at $P<0.05$.

\section{Results}

\section{Baseline characteristics and nutrient intakes of subjects}

General characteristics and mean daily nutrient intakes of the study population are presented in Table 1 . There were no significant differences between groups in any of the baseline variables measured, except that a greater proportion of London subjects had attained a higher education (tertiary) compared with subjects from Accra (57 v. $38 \% ; P=0.001)$. Allele frequencies for the MTHFR $677 \mathrm{C} \rightarrow \mathrm{T}$ mutation were $10 \%$ in London and $8 \%$ in Accra; overall, the prevalence of the TT genotype was $0.5 \%$. There was a greater proportion of supplement users in London compared with Accra (25 v. $10 \% ; P=0.004)$. Reported intakes of vitamins $\mathrm{B}_{6}$ and $\mathrm{B}_{12}$ were higher in London compared with Accra (by $15 \%$, $P=0.03$ and $6 \%, P=0.04$, respectively). However, reported folate intakes (diet and supplements) were $20 \%$ lower in London compared with Accra $(P<0 \cdot 001)$.

The main dietary sources of folate in London and Accra are shown in Table 2. The largest sources of folate in London were Ghanaian soups and bean dishes, accounting for $33 \%$ of folate intake. This was followed by vegetable stews and fermented maize products $(18 \%)$. In addition, foods such as breakfast cereals, fruits and fruit juices and mixed vegetables also contributed to folate intake in London (accounting for $20 \%$ ). In Accra, the largest sources of folate were from Ghanaian soups, vegetable stews and bean dishes (61\%). Other dishes that contributed to folate intake were fermented maize products and fruits $(20 \%)$.

\section{Biomarkers of folate and vitamin $B_{12}$ status}

The mean serum folate, erythrocyte folate, plasma homocysteine and serum vitamin $\mathrm{B}_{12}$ in subjects from London and Accra are shown in Table 3. Serum and erythrocyte folate was higher (by 44 and $30 \%$, respectively; $P<0.001$ ) and plasma homocysteine was lower (by $26 \% ; P<0.001$ ) in participants from London compared with those from Accra. The differences between London and Accra were still significant $(P=0.001)$ after controlling for age, sex, BMI, educational level, alcohol intake and the MTHFR $677 \mathrm{C} \rightarrow \mathrm{T}$ genotype.

There were no significant correlations between total folate intake (diet and supplements) and serum folate or erythrocyte folate in either London $(r 0 \cdot 208, P=0.068 ; r 0 \cdot 189, P=0.103$; respectively) or Accra ( $r$ 0.046 and $r$ 0.071, respectively; $P>0.05)$. There were no significant correlations between dietary folate intake in non-supplement users and serum or erythrocyte folate in either London $(r \quad 0.155$ and $r 0.028$, respectively; $P>0.05)$ or Accra ( $r 0.041$ and $r 0.032$, respectively; $P>0.05)$. There was, however, a positive correlation between supplemental folate intake and erythrocyte folate in London and Accra $(r$ 0.419, $P<0.001 ; r$ 0.225, $P=0.005$, respectively). There was a significant positive correlation between serum folate and erythrocyte folate in London ( $r 0.385 ; P=0.001)$ and Accra $(r 0.352 ; P<0.001)$. Regression analysis confirmed that serum folate and folic acid supplement use were predictors of erythrocyte folate in both London and Accra $(P=0 \cdot 001)$. No significant association was found between MTHFR $677 \mathrm{C} \rightarrow \mathrm{T}$ genotype and serum folate or erythrocyte folate in either population $(P>0 \cdot 05)$.

There were negative correlations between serum folate and plasma homocysteine (London, $r-0.192, P=0.09$; Accra, $r-0.325, P<0.001)$ and erythrocyte folate and plasma homocysteine (London, $r-0 \cdot 388, P=0.001$; Accra, $r-0.290$, $P<0.001)$. Regression analysis showed that erythrocyte folate was the main predictor of plasma homocysteine concentrations in London $(P=0.001)$ while in Accra the main predictor was male sex $(P=0.001)$. There were negative correlations between serum vitamin $\mathrm{B}_{12}$ and plasma homocysteine in both London $(r-0.289 ; P=0.01)$ and Accra $(r-0.140 ; P=0.08)$. There was no association between the MTHFR $677 \mathrm{C} \rightarrow \mathrm{T}$ genotype and plasma homocysteine in either location $(P>0 \cdot 05)$.

Table 4 shows the biomarkers of folate status in folic acid supplement users and non-users in London and Accra. Compared with non-supplement users, folic acid supplement users had higher serum folate (by $24 \%$ in London, $P=0.09$, and $67 \%$ in Accra, $P=0.008$ ) and erythrocyte folate (by $33 \%$ in London, $P<0.001$, and $32 \%$ in Accra, $P=0.006$ ), and lower plasma homocysteine (by $16 \%$ in London, $P=0 \cdot 150$, and $21 \%$ in Accra, $P=0 \cdot 01)$. Folic acid supplement 
Table 1. Demographic characteristics and nutrient intakes of study participants

\begin{tabular}{|c|c|c|c|c|c|c|}
\hline & \multicolumn{3}{|c|}{ London } & \multicolumn{3}{|c|}{ Accra } \\
\hline & Men $(n$ 43) & Women ( $n$ 37) & All $(n 80)$ & Men $(n$ 86) & Women $(n 74)$ & All $(n$ 160) \\
\hline \multicolumn{7}{|l|}{ Age (years) } \\
\hline Mean & $37 \cdot 3$ & 38.7 & 37.9 & $36 \cdot 8$ & $38 \cdot 1$ & $37 \cdot 4$ \\
\hline SEM & $1 \cdot 1$ & $1 \cdot 1$ & $0 \cdot 8$ & $0 \cdot 8$ & 0.0 & 0.6 \\
\hline \multicolumn{7}{|l|}{ BMI $\left(\mathrm{kg} / \mathrm{m}^{2}\right)$} \\
\hline Mean & 27.5 & 29.5 & $28 \cdot 4$ & $26 \cdot 5$ & $30 \cdot 2$ & $28 \cdot 1$ \\
\hline SEM & 0.5 & 0.9 & 0.4 & 0.5 & $0 \cdot 7$ & 0.4 \\
\hline \multicolumn{7}{|l|}{ Length of stay (years) } \\
\hline Median & 6 & 8 & 6 & 27 & 30 & 29 \\
\hline Range & $5-33$ & $5-38$ & $5-38$ & $6-50$ & $5-50$ & $5-50$ \\
\hline \multicolumn{7}{|l|}{ Educational level (\%) } \\
\hline Primary & 7 & 11 & 9 & 14 & 16 & 15 \\
\hline Secondary & 26 & 43 & 34 & 42 & 53 & 47 \\
\hline Tertiary & 67 & 46 & $57^{\star \star}$ & 44 & 31 & 38 \\
\hline \multicolumn{7}{|l|}{ Occupation (\%) } \\
\hline Professional and managerial & 47 & 43 & 45 & 49 & 50 & 49 \\
\hline Skilled workers & 12 & 30 & 20 & 11 & 24 & 17 \\
\hline Non-skilled workers & 30 & 8 & 20 & 29 & 15 & 23 \\
\hline Students & 12 & 19 & 15 & 12 & 11 & 11 \\
\hline \multicolumn{7}{|l|}{ Religion (\%) } \\
\hline Christianity & 98 & 100 & 99 & 98 & 97 & 98 \\
\hline Others & 2 & 0 & 1 & 1 & 3 & 3 \\
\hline \multicolumn{7}{|l|}{ Smoking (\%) } \\
\hline Current smoker & 0 & 0 & 0 & 0 & 0 & 0 \\
\hline Ex-smoker & 14 & 0 & 14 & 9 & 1 & 10 \\
\hline Non-smoker & 86 & 100 & 86 & 91 & 99 & 90 \\
\hline Use of folate-containing supplements (\%) & 16 & 35 & $25^{\star}$ & 5 & 16 & 10 \\
\hline \multicolumn{7}{|l|}{ MTHFR $677 \mathrm{C} \rightarrow \mathrm{T}(n) \ddagger$} \\
\hline CC & 37 & 33 & 70 & 70 & 63 & 133 \\
\hline CT & 4 & 3 & 7 & 5 & 6 & 11 \\
\hline TT & 0 & 0 & 0 & 1 & 0 & 1 \\
\hline \multicolumn{7}{|l|}{ Vitamin $B_{6}(\mathrm{mg} / \mathrm{d})$} \\
\hline Median & 1.4 & $1 \cdot 6$ & $1.5+\dagger$ & 1.5 & $1 \cdot 3$ & $1 \cdot 3$ \\
\hline Range & $0.5-12 \cdot 0$ & $0.5-11.4$ & $0.5-12 \cdot 0$ & $0.5-6.5$ & $0.4-9.1$ & $0.4-9.1$ \\
\hline \multicolumn{7}{|l|}{ Vitamin $B_{12}(\mu \mathrm{g} / \mathrm{d})$} \\
\hline Median & $7 \cdot 3$ & 4.4 & $5.5 \dagger$ & 3.5 & $5 \cdot 0$ & $5 \cdot 2$ \\
\hline Range & $0.5-30.5$ & $0.2-24.3$ & $0.5-30.5$ & $0 \cdot 8-20 \cdot 1$ & $0.8-19.7$ & $0 \cdot 8-20 \cdot 1$ \\
\hline \multicolumn{7}{|c|}{ Food folate (includes synthetic folic acid in foods) $(\mu \mathrm{g} / \mathrm{d})$} \\
\hline Median & 388 & 391 & $389+1 \dagger$ & 596 & 553 & 567 \\
\hline Range & $121-996$ & $93-1220$ & $93-1220$ & $180-1472$ & $206-1141$ & $180-1472$ \\
\hline \multicolumn{7}{|l|}{ Folate (diet and supplements) $(\mu \mathrm{g} / \mathrm{d})$} \\
\hline Median & 417 & 507 & 465††† & 602 & 573 & 581 \\
\hline Range & $121-996$ & $93-1220$ & $93-1220$ & $210-1472$ & $206-1324$ & $206-1472$ \\
\hline \multicolumn{7}{|l|}{ Alcohol $(\mathrm{g} / \mathrm{d})$} \\
\hline Median & 0 & 0 & 0 & 0 & 0 & 0 \\
\hline Range & $0-23$ & $0-13$ & $0-23$ & $0-4$ & $0-17$ & $0-17$ \\
\hline
\end{tabular}

Proportion was significantly different from that of the Accra group: ${ }^{*} P=0.004,{ }^{* *} P=0.001$ ( $\chi^{2}$ test or Fisher's exact test).

Median value was significantly different from that of the Accra group: $\dagger P=0.04$, $\uparrow \dagger P=0.03$, $† \dagger \dagger P<0.001$ (Mann-Whitney $U$ test).

‡London, $n$ 77; Accra, $n 145$.

users in London had higher erythrocyte folate $(28 \%, P=0 \cdot 09)$ and lower plasma homocysteine $(22 \%, P=0.03)$ compared with folic acid supplement users in Accra. However, nonusers of folic acid supplements from London also had significantly higher serum and erythrocyte folate (by $48 \%$, $P=0.001$ and $27 \%, P<0.001$, respectively) and lower plasma homocysteine (by $27 \% ; P<0.001$ ) compared with non-users from Accra.

\section{Discussion}

The present study compared folate status in a first-generation Ghanaian migrant population living in London with an urban population in Accra, Ghana. Results showed that reported folate intakes in London were significantly lower compared with those in Accra even though folate from supplements was added to daily intakes and there were more supplement users in London. The higher folate intakes in Accra resulted from large reported intakes of traditional Ghanaian vegetable stews and soups in addition to other foods processed from fermented maize products (Table 3). Reported median folate intakes in subjects from London (417 $\mu \mathrm{g} / \mathrm{d}$ in men and $507 \mu \mathrm{g} / \mathrm{d}$ in women) were higher than median intakes of the average UK population $(333 \mu \mathrm{g} / \mathrm{d}$ in men and $255 \mu \mathrm{g} / \mathrm{d}$ in women) ${ }^{(19)}$.

Despite reporting lower intakes of folate, subjects from London had a more favourable folate status than subjects in Accra, with higher serum and erythrocyte folate $(P<0.001)$ and lower plasma homocysteine concentrations $(P<0 \cdot 001)$. It is unclear why there were such marked differences between 
Table 2. Major foods contributing to folate intake in study participants (\% total folate intake)

\begin{tabular}{|c|c|c|}
\hline & London ( $n$ 80) & Accra $(n 160)$ \\
\hline Light, palm nut or peanut soup & 20 & 22 \\
\hline $\begin{array}{l}\text { Bean dishes (bean stew, } \\
\text { rice and beans) }\end{array}$ & 13 & 19 \\
\hline $\begin{array}{l}\text { Spinach*/garden egg stews, okro } \\
\text { stews and soups }\end{array}$ & 9 & 20 \\
\hline $\begin{array}{l}\text { Fermented maize dishes (banku, } \\
\text { kenkey, porridges) }\end{array}$ & 9 & 11 \\
\hline Fruit juice & 6 & - \\
\hline Ghanaian stew or gravy & 6 & - \\
\hline Fruits & 5 & 9 \\
\hline Breakfast cereals & 5 & - \\
\hline Mixed vegetables & 4 & - \\
\hline
\end{tabular}

* Participants in Accra consumed 'kontomire' leaves, which are similar to spinach but not found commonly in the UK.

reported dietary intakes and biomarkers in these two populations. Although misreporting of dietary intake is known to occur with the $24 \mathrm{~h}$ recall ${ }^{(20,21)}$ and this method of dietary assessment has not been validated for B vitamin intake in this population, folate intakes in the present study were based on an average of three $24 \mathrm{~h}$ recalls, which included a weekend day, and there was a similar proportion of underreporters in both London and Accra (30 and $21 \%$, respectively). A possible explanation for the difference in the dietary folate intake observed between subjects from London and Accra is the use of slightly different databases to determine folate intakes. The folate data generated for subjects in Accra, who typically consumed traditional Ghanaian foods, came mainly from our recently generated database on the nutritional composition of commonly consumed Ghanaian dishes, whereas the folate data for the subjects in London were determined from the recently generated database in combination with McCance and Widdowson's Food Composition Tables. However, the folate content of foods in the two databases has been determined by different analytical methods; the recently generated database used the microbiological assay with tri-enzyme extraction according to the method of Tamura $^{(16)}$, whereas the Food Composition Tables used the microbiological assay with the traditional conjugase treatment alone. The application of tri-enzyme extraction has been reported to increase considerably the measurable folate in single foods and in composite meals ${ }^{(16,22)}$, and this could account for the higher folate intakes in the Accra population in the present study.

One possible explanation for the higher blood folate concentrations in the London population may be the higher consumption of folic acid from fortified foods and supplements. Folic acid has superior bioavailability compared with natural folates $^{(23)}$ and it is well established that higher intakes of foods naturally rich in folates are a relatively ineffective means of increasing folate status compared with equivalent intakes of folic acid-fortified food ${ }^{(24)}$. Breakfast cereals were rarely consumed in Accra but contributed to $5 \%$ of the folate intake in London. Also, multivitamins containing folic acid were consumed by $25 \%$ of participants from London compared with $10 \%$ of participants from Accra and there was a strong association between reported use of folic acid supplements and erythrocyte folate concentrations in both 
Table 4. Biomarkers of folate status in users $v$. non-users of folic acid supplements (Medians and ranges)

\begin{tabular}{|c|c|c|c|c|c|c|c|c|}
\hline & \multicolumn{4}{|c|}{ Folic acid supplement users } & \multicolumn{4}{|c|}{ Non-users of folic acid supplements } \\
\hline & \multicolumn{2}{|c|}{ London (n 20) } & \multicolumn{2}{|c|}{ Accra $(n 16)$} & \multicolumn{2}{|c|}{ London (n 60) } & \multicolumn{2}{|c|}{ Accra $(n 144)$} \\
\hline & Median & Range & Median & Range & Median & Range & Median & Range \\
\hline Serum folate $(\mathrm{nmol} / \mathrm{l})$ & $13 \cdot 8$ & $5 \cdot 9-26 \cdot 5$ & $12 \cdot 5$ & $3 \cdot 6-24 \cdot 0$ & $11 \cdot 1^{\star \star}$ & $3 \cdot 2-26 \cdot 1$ & 7.5 & $2 \cdot 3-23 \cdot 6$ \\
\hline Erythrocyte folate (nmol/l) & 888 & $374-2216$ & 696 & $229-1695$ & $668^{\star \star *}$ & $419-1044$ & 526 & $181-1172$ \\
\hline Plasma homocysteine $(\mu \mathrm{mol} / \mathrm{l})$ & $8 \cdot 6^{\star}$ & $6 \cdot 2-16 \cdot 9$ & $11 \cdot 0$ & $9 \cdot 0-23 \cdot 9$ & $10 \cdot 2^{\star \star \star}$ & $5 \cdot 6-17 \cdot 8$ & $13 \cdot 9$ & $6 \cdot 9-28 \cdot 9$ \\
\hline
\end{tabular}

Median value was significantly different from that of the Accra group: ${ }^{\star} P=0.03,{ }^{\star *} P=0.001,{ }^{\star \star \star} P<0.001$ (Mann-Whitney $U$ test).

locations $(P<0 \cdot 001)$. However, it was evident that folic acid supplement use was not solely responsible for the differences in biomarkers observed between the two populations, since non-users of folic acid supplements in London had significantly higher serum and erythrocyte folate $(P=0.001$ and $P<0.001$, respectively) and significantly lower plasma homocysteine $(P=0 \cdot 001)$ than non-users in Accra. Similarly, supplement users in London had higher erythrocyte folate $(P=0.09)$ and lower plasma homocysteine $(P=0.03)$ than supplement users in Accra. This suggests that folic acid from fortified foods may have made a substantial contribution to the differences observed in these biomarkers between London and Accra.

Estimation of the contribution of folic acid from fortified foods to the total folate intake in the present study was not possible since it was difficult to obtain information on the brands of breakfast cereal consumed by participants. Different manufacturers fortify their cereals with different amounts of folic acid and cereals are fortified with folic acid at higher levels than the values given in the current nutrient database, which has not been updated for 5 years. Furthermore, the nutritional package used in the present study did not separate natural folate from synthetic folic acid used as fortificant. It is possible that participants from London were consuming some other foods that were fortified with folic acid, which were not accounted for in the nutritional database. Recently, certain brands of margarines and fruit juice have been fortified with folic acid.

Although we used an updated database (which included information on folate content of Ghanaian foods) to estimate folate intake we did not find a relationship between dietary folate intakes and serum or erythrocyte folate as reported in some studies ${ }^{(25-27)}$. However, other studies have found no association between dietary folate intake assessed by FFQ and $7 \mathrm{~d}$ weighed record and serum or erythrocyte folate in healthy populations ${ }^{(28,29)}$. Possible reasons for the lack of association in the present study are underestimation of folic acid intake from fortified foods and misreporting of food intake by participants. Nutrient intake in the present study was by the $24 \mathrm{~h}$ recall and a major limitation of this method is the inability to remember foods eaten and accurate description of foods ${ }^{(30)}$. It is possible that the lack of agreement between folate intake and blood folate values are related to the reporting of food intake in this group of individuals because we observed no relationship between dietary vitamin $B_{12}$ intake and serum vitamin $B_{12}$ concentrations in the present study $(P>0.05)$. Furthermore, the relatively high reported dietary folate intakes in our population are not reflected in the serum folate concentrations $(10.9 \mathrm{nmol} / 1 \mathrm{in}$ men and $12.0 \mathrm{nmol} / \mathrm{l}$ in women) which are lower than those reported in the average UK population $(18.8 \mathrm{nmol} / 1$ in men and $21.0 \mathrm{nmol} / 1$ in women) ${ }^{(31)}$, although they are comparable with serum folate concentrations in populations of African descent in the USA $(12.6 \mathrm{nmol} / \mathrm{l}$ in men and $15.5 \mathrm{nmol} / \mathrm{l}$ in women $)^{(32)}$. However, erythrocyte folate concentrations $(675 \mathrm{nmol} / 1$ in men and $757 \mathrm{nmol} / \mathrm{l}$ in women) in subjects from London were comparable with those of the average UK population $(633 \mathrm{nmol} / \mathrm{l}$ in men and $610 \mathrm{nmol} / \mathrm{l}$ in women) ${ }^{(31)}$. The present results suggest that further research should be conducted in how to obtain reliable dietary intake data from this type of population.

The significantly higher erythrocyte folate concentrations in London participants were accompanied by significantly lower plasma homocysteine concentrations. Plasma homocysteine was $26 \%$ lower in London compared with Accra. The median concentrations found in men $(10.9 \mu \mathrm{mol} / \mathrm{l})$ and women $(8.4 \mu \mathrm{mol} / \mathrm{l})$ in London were similar to previously reported measurements of plasma homocysteine in populations of African descent in the UK and USA ${ }^{(1,33)}$. Mean plasma homocysteine concentrations in London participants were within the range considered normal $(<15 \mu \mathrm{mol} / \mathrm{l})$; however, men from Accra had a median value exceeding this $(16.0 \mu \mathrm{mol} / \mathrm{l})$. Plasma homocysteine concentrations above $12 \mu \mathrm{mol} / 1$ have been consistently associated with vascular disease $^{(34)}$. By this definition hyperhomocysteinemia is prevalent in the healthy Accra population and may have implications for stroke incidence.

The main predictors of plasma homocysteine in our population were male sex and erythrocyte folate concentrations. Population studies generally show that increasing age, male sex, smoking, coffee consumption, high blood pressure and the MTHFR $677 \mathrm{C} \rightarrow \mathrm{T}$ polymorphism are among the factors associated with plasma homocysteine concentrations ${ }^{(35-37)}$. The present study did not find any association between plasma homocysteine and age, which may be due to the narrow age range in our population (25-50 years) or the relatively small sample size. Similar to other population studies $^{(36,38,39)}$, the present study showed plasma homocysteine concentrations to be correlated with blood folates and vitamin $\mathrm{B}_{12}$.

The MTHFR $677 \mathrm{C} \rightarrow \mathrm{T}$ mutation was not associated with plasma homocysteine concentrations in the present study, despite the fact that the mutation is a known determinant of homocysteine concentrations and plasma folate ${ }^{(17)}$. However, 
the prevalence of the MTHFR $677 \mathrm{C} \rightarrow \mathrm{T}$ mutation was low in our population, a finding consistent with other studies in populations of African descent ${ }^{(10-12)}$. The lack of association of the MTHFR $677 \mathrm{C} \rightarrow \mathrm{T}$ mutation with plasma homocysteine may be due to the low prevalence of the TT genotype and the sample size, which may have been too small to detect such a relationship. The low prevalence of the MTHFR $677 \mathrm{C} \rightarrow \mathrm{T}$ mutation suggests that folate status in London and Accra participants is mainly a reflection of dietary factors.

\section{Conclusion}

Migration to the UK leads to an improvement in biomarkers of folate status in Ghanaian migrants from London compared with a matched population from Accra. Findings of the sample may be generalisable to a similar group with the same educational and socio-economic status in London and Accra. However, this sample may not be representative of the total Ghanaian population in the UK and Ghana. Since an improved folate status is associated with prevention of stroke as well as other conditions, there is a need to undertake large-scale epidemiological studies within the general adult Ghanaian population to confirm these findings.

\section{Acknowledgements}

We gratefully acknowledge the assistance of Dr Roy Sherwood and the staff of the Clinical Biochemistry Department at King's College Hospital in conducting the assays of serum and erythrocyte folate concentrations. The authors also acknowledge sponsorship of the Ministry of Health and School of Allied Health Sciences, University of Ghana.

M. O. was involved in patient recruitment, collection of data, statistical analysis and manuscript writing. J. T. was involved in experiment design and manuscript writing. E. W. was involved in collection of data and manuscript writing. M. P. was involved in experiment design, statistical analysis and manuscript writing.

The authors do not have any conflicts of interest to declare.

\section{References}

1. Cappuccio FP, Bell R, Perry IJ, et al. (2002) Homocysteine levels in men and women of different ethnic and cultural background living in England. Atherosclerosis 164, 95-102.

2. Stewart JA, Dundas R, Howard RS, et al. (1999) Ethnic differences in incidence of stroke: prospective study with stroke register. BMJ 318, 967-971.

3. Wolfe CD, Corbin DO, Smeeton NC, et al. (2006) Estimation of the risk of stroke in black populations in Barbados and South London. Stroke 37, 1986-1990.

4. Larsson SC, Mannisto S, Virtanen MJ, et al. (2008) Folate, vitamin $\mathrm{B}_{6}$, vitamin $\mathrm{B}_{12}$, and methionine intakes and risk of stroke subtypes in male smokers. Am J Epidemiol 167, 954-961.

5. Wang X, Qin X, Demirtas H, et al. (2007) Efficacy of folic acid supplementation in stroke prevention: a meta-analysis. Lancet 369, 1876-1882.

6. Hassan A, Hunt BJ, O'Sullivan M, et al. (2004) Homocysteine is a risk factor for cerebral small vessel disease, acting via endothelial dysfunction. Brain 127, 212-219.
7. Ueland PM, Refsum H, Stabler SP, et al. (1993) Total homocysteine in plasma or serum: methods and clinical applications. Clin Chem 39, 1764-1779.

8. Anonymous (1998) Lowering blood homocysteine with folic acid based supplements: meta-analysis of randomized trials. Homocysteine Lowering Trialists' Collaboration. BMJ 316, 894-898.

9. Brouwer IA, van Dusseldorp M, West CE, et al. (1999) Dietary folate from vegetables and citrus fruit decreases plasma homocysteine concentrations in humans in a dietary controlled trial. $J$ Nutr 129, 1135-1139.

10. Franco RF, Araujo AG, Guerreiro JF, et al. (1998) Analysis of the $677 \mathrm{C} \rightarrow \mathrm{T}$ mutation of the methylenetetrahydrofolate reductase gene in different ethnic groups. Thromb Haemost 79, 119-121.

11. Rosenberg N, Murata M, Ikeda Y, et al. (2002) The frequent 5,10-methylenetetrahydrofolate reductase C677T polymorphism is associated with a common haplotype in whites, Japanese, and Africans. Am J Hum Genet 70, 758-762.

12. Adjalla CE, Amouzou EK, Sanni A, et al. (2003) Low frequency of mutated methylenetetrahydrofolate reductase $677 \mathrm{C} \rightarrow \mathrm{T}$ and $1298 \mathrm{~A} \rightarrow \mathrm{C}$ genetics single nucleotide polymorphisms (SNPs) in Sub-Saharan populations. Clin Chem Lab Med 41, 1028-1032.

13. Kalra L, Iveson E, Rambaran C, et al. (2008) Homocysteine, migration and early vascular impairment in people of African descent. Heart 94, 1171-1174.

14. Patel JV, Vyas A, Cruickshank JK, et al. (2006) Impact of migration on coronary heart disease risk factors: comparison of Gujaratis in Britain and their contemporaries in villages of origin in India. Atherosclerosis 185, 297-306.

15. Krause K (2008) Transnational therapy networks among Ghanaians in London. J Ethn Migr Stud 34, 235-252.

16. Tamura T (1998) Determination of food folate. J Nutr Biochem 9, 285-293.

17. Frosst P, Blom HJ, Milos R, et al. (1995) A candidate genetic risk factor for vascular disease: a common mutation in methylenetetrahydrofolate reductase. Nat Genet 10, 111-113.

18. Willett WC, Howe GR \& Kushi LH (1997) Adjustment for total energy intake in epidemiologic studies. Am J Clin Nutr $\mathbf{6 5}$, $1220 \mathrm{~S}-1228 \mathrm{~S}$

19. Henderson L, Irving K, Gregory J, et al. (2003) National Diet and Nutrition Survey: adults aged 19 to 64 years. Vol. 3 . Vitamin and mineral intakes and urinary analytes. http://www. food.gov.uk/multimedia/pdfs/ndnsv3.pdf.

20. Kipnis V, Subar AF, Midthune D, et al. (2003) Structure of dietary measurement error: results of the OPEN Biomarker Study. Am J Epidemiol 158, 14-21.

21. Subar AF, Kipnis V, Troaino RP, et al. (2003) Using intake biomarkers to evaluate the extent of dietary misreporting in a large sample of adults: The Observing Protein and Energy Nutrition (OPEN) study. Am J Epidemiol 158, 1-13.

22. Martin JI, Landen WO Jr, Soliman AG, et al. (1990) Application of a tri-enzyme extraction for total folate determination in foods. $J$ Assoc Off Anal Chem 73, 805-808.

23. Sauberlich HE, Kretsch MJ, Skala JH, et al. (1987) Folate requirement and metabolism in nonpregnant women. Am J Clin Nutr 46, 1016-1028.

24. Cuskelly GJ, McNulty H \& Scott JM (1996) Effect of increasing dietary folate on red-cell folate: implications for prevention of neural tube defects. Lancet 347, 657-659.

25. Garry PJ, Goodwin JS \& Hunt WC (1984) Folate and vitamin $\mathrm{B}_{12}$ status in a healthy elderly population. $J$ Am Geriatr Soc 32, 719-726.

26. Selhub J, Jacques PF, Wilson PW, et al. (1993) Vitamin status and intake as primary determinants of homocysteinemia in an elderly population. JAMA 270, 2693-2698. 
27. Green TJ, Allen OB \& O'Connor DL (1998) A three-day weighed food record and a semiquantitative food frequency questionnaire are valid measures for assessing the folate and vitamin $B_{12}$ intakes of women aged 16 to 19 years. $J$ Nutr 128, 1665-1671.

28. Alfthan G, Laurinen MS, Valsta LM, et al. (2003) Folate intake, plasma folate and homocysteine status in a random Finnish population. Eur J Clin Nutr 57, 81-88.

29. Pufulete M, Emery PW, Nelson M, et al. (2002) Validation of a short food frequency questionnaire to assess folate intake. $\mathrm{Br} J$ Nutr 87, 383-390.

30. Margetts BM \& Nelson M (1997) Assessment of food consumption and nutrient intake. Section 6.7. Past intake. In Design Concepts in Nutritional Epidemiology 2nd ed., pp. 123-143 [BM Margetts and M Nelson, editors]. New York: Oxford University Press.

31. Ruston D, Hoare J, Henderson L, et al. (2004) National Diet and Nutrition Survey: adults aged 19 to 64 years. Vol 4. Nutritional status (anthropometry and blood analytes), blood pressure and physical activity. http://www.food.gov.uk/multimedia/pdfs/ndnsfour.pdf

32. Kant AK \& Graubard BL (2007) Ethnicity is an independent correlate of biomarkers of micronutrient intake and status in American adults. J Nutr 137, 2456-2463.

33. Gerhard GT, Sexton G, Malinow MR, et al. (1998) Premenopausal black women have more risk factors for coronary heart disease than white women. Am J Cardiol 82, 1040-1045.
34. Wald DS, Law M \& Morris JK (2002) Homocysteine and cardiovascular disease: evidence on causality from a meta-analysis. BMJ 325, 1202-1208.

35. El-Sammak M, Kandil M, El-Hifni S, et al. (2004) Elevated plasma homocysteine is positively associated with age independent of C677T mutation of the methylenetetrahydrofolate reductase gene in selected Egyptian subjects. Int J Med Sci $\mathbf{1}$, $181-192$.

36. Refsum H, Nurk E \& Smith AD (2006) The Hordaland Homocysteine Study: a community-based study of homocysteine, its determinants, and associations with disease. J Nutr 136, 1731 S-1740S

37. Goessens BMB, van der Graaf Y, Olijhoek JK, et al. (2007) The course of vascular risk factors and the occurrence of vascular events in patients with symptomatic peripheral arterial disease. $J$ Vasc Surg 45, 47-54.

38. Hoey L, McNulty H, Askin N, et al. (2007) Effect of a voluntary food fortification policy on folate, related B vitamin status, and homocysteine in healthy adults. Am J Clin Nutr 86, $1405-1413$.

39. Drogan D, Klipstein-Grobusch K, Wans S, et al. (2004) Plasma folate as marker of folate status in epidemiological studies: the European Investigation into Cancer and Nutrition (EPIC)-Potsdam study. Br J Nutr 92, 489-496. 